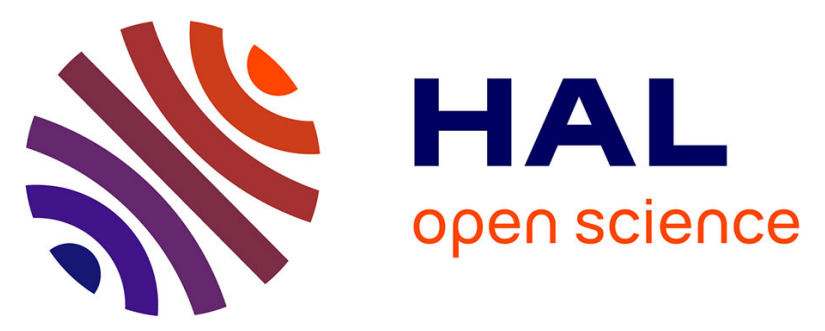

\title{
New insights in reactive extraction mechanisms of organic acids: An experimental approach for 3-hydroxypropionic acid extraction with tri-n-octylamine
}

Florian Chemarin, Marwen Moussa, Morad Chadni, Brigitte Pollet, Pascale Lieben, Florent Allais, Ioan-Cristian Trelea, Violaine Athes-Dutour

\section{To cite this version:}

Florian Chemarin, Marwen Moussa, Morad Chadni, Brigitte Pollet, Pascale Lieben, et al.. New insights in reactive extraction mechanisms of organic acids: An experimental approach for 3hydroxypropionic acid extraction with tri-n-octylamine. Separation and Purification Technology, 2017, 179, pp.523-532. 10.1016/j.seppur.2017.02.018 . hal-01530851

\section{HAL Id: hal-01530851 \\ https://hal.science/hal-01530851}

Submitted on 4 Jul 2017

HAL is a multi-disciplinary open access archive for the deposit and dissemination of scientific research documents, whether they are published or not. The documents may come from teaching and research institutions in France or abroad, or from public or private research centers.
L'archive ouverte pluridisciplinaire HAL, est destinée au dépôt et à la diffusion de documents scientifiques de niveau recherche, publiés ou non, émanant des établissements d'enseignement et de recherche français ou étrangers, des laboratoires publics ou privés.

\section{()(1)(2)}

Distributed under a Creative Commons Attribution - ShareAlikel 4.0 International 
New insights in reactive extraction mechanisms of organic acids: an experimental approach for 3-

\section{hydroxypropionic acid extraction with tri-n-octylamine}

F. Chemarin ${ }^{a, b}$, M. Moussa ${ }^{b}$, M. Chadni ${ }^{b}$, B. Pollet ${ }^{b}$, P. Lieben ${ }^{b}$, F. Allais ${ }^{a, b}$, I.C. Trelea ${ }^{b}$, V. Athès $^{b^{*}}$

${ }^{\text {a }}$ Chaire Agro-Biotechnologies Industrielles (ABI), AgroParisTech, CEBB, 3 rue des Rouges Terres, Route de Bazancourt, F-51110 Pomacle, France

${ }^{\mathrm{b}}$ UMR GMPA, AgroParisTech, INRA, Université Paris-Saclay, F-78850, Thiverval-Grignon, France

* Corresponding author: UMR GMPA, AgroParisTech, INRA, Université Paris-Saclay, F-78850, Thiverval-Grignon, France. E-mail address: violaine.athes-dutour@inra.fr

\section{Abstract}

A detailed study of 3-hydroxypropionic acid (3-HP) reactive extraction with tri-n-octylamine (TOA) is proposed for the first time. It aims at uncovering some solvent-solutes interactions and providing global mechanisms to better understand and design the reactive liquid-liquid extraction of 3-HP in a biotechnological process. Eleven solvents of similar molecular sizes and several chemical types (alcohols, esters and alkanes) were investigated to understand their role on the extraction ability. Alcohols were found to be the best solvents thanks to their $\mathrm{H}$-bond donor characteristic and water loading that allowed good solvation of the acid-amine complexes. Further investigations were then undertaken, for $n$-decanol and oleyl alcohol as solvents, varying acid $(0.0028-0.56 \mathrm{~mol} / \mathrm{L}$ corresponding to $0.25-50 \mathrm{~g} / \mathrm{L})$ and amine $(0-2.3 \mathrm{~mol} / \mathrm{L}$ corresponding to $0-100 \% \mathrm{v} / \mathrm{v})$ concentrations. At $0.011 \mathrm{~mol} / \mathrm{L}(1 \mathrm{~g} / \mathrm{L})$ of $3-\mathrm{HP}$, maximum extraction yields of $77 \%$ for $n$-decanol and $51 \%$ for oleyl alcohol were found for $0.46 \mathrm{~mol} / \mathrm{L} \mathrm{TOA}(20 \% \mathrm{v} / \mathrm{v})$. The initial TOA purity proved to have a major impact on the extraction yield at low initial acid concentration $(<0.1 \mathrm{~mol} / \mathrm{L}=10 \mathrm{~g} / \mathrm{L})$. Impurities from the TOA manufacturing process were identified as $n$-octylamine and di- $n$-octylamine and quantified in the aqueous phase after extraction. Their major effect on the extraction yield has been assessed (up to $86 \%$ decrease). 
1 Keywords

2 Solvent extraction; organic acid; active solvent; tri- $n$-octylamine impurity; In Situ Product Recovery; 
1 Abbreviations

2 3-HP: 3-hydroxypropionic acid

3 AH: acid under non-dissociated form

$4[A H]_{H P L C}$ : total concentration of 3-HP under all forms in water as determined using HPLC (mol/L)

5 ANOVA: analysis of variance

6 B: organic base

$7 \quad B H^{+}$: conjugate acid of $\mathrm{B}$

$8 \quad H^{+}$: hydrogen ion

$9 \quad K_{A}^{A H}$ : dissociation constant of 3-HP in water

$10 K_{A}^{O A}$ : dissociation constant of $n$-octylammonium in water

$11 K_{w}$ : ionic product of water

$12[O A]_{L C M S}$ : total concentration of $n$-octylamine (and di-n-octylamine) in water under all forms as 13 determined using UHPLC-HRMS (mol/L)

14 p: stoichiometric coefficient

$15 p$ : p-value of ANOVA tests

$16 p H_{t h}$ : calculated $\mathrm{pH}$ according to $[A H]_{H P L C}$ only

$17 p H_{t h, O A}$ : calculated $\mathrm{pH}$ according to $[A H]_{H P L C}$ and $[O A]_{L C M S}$

18 q: stoichiometric coefficient

$19 R_{3} N$ : tertiary amine

20 TOA: tri- $n$-octylamine

21 Y: extraction yield

22 Subscript and superscript:

23 aq: in the aqueous phase

24 eq: at the equilibrium

25 ini: initially, before extraction

26 org: in the organic phase 


\section{Introduction}

It is now recognized that 3-hydroxypropionic acid (3-HP) is a valuable platform molecule that can be used as a building-block for the production of new polymers like polyesters and acrylic acid derivatives such as acrylates or acrylamides [1]. This molecule is currently not widely used due to its exclusive and difficult synthesis via chemical pathways including transformation of petrochemical products such as propylene but is expected to exhibit a significant growth in the next years. Indeed, it has been referred as one of the Top 10 "chemical opportunities from biorefinery carbohydrates" [2]. Lately, research has focused on the production of 3-HP using biotechnologies with natural $[3,4]$ and modified $[5,6]$ micro-organisms able to convert glycerol or glucose into 3-HP [7]. Other substrates like $\mathrm{CO}_{2}[8,9]$ and $\mathrm{C} 5$ sugars $[10,11]$ are also currently studied. Biotechnology is considered as a promising route for the sustainable and efficient production of $3 \mathrm{HP}$ but one of the main drawbacks of this approach is the inhibitory effect the products can have on the micro-organisms, limiting productivity and final concentrations to quite low amounts, which is particularly true for the 3-HP production [7]. In this context, in-situ product recovery (ISPR) seems to be a promising approach because the simultaneous removal of the product from the bioconversion medium could favor higher yields, productivity and concentrations. Liquid-liquid reactive extraction for organic acids' recovery is known to be particularly efficient and selective for dilute media as an ISPR technique in biotechnological processes and can prevent toxic metabolites and/or products from accumulating $[12,13]$

Current concentrations of 3-HP in bioconversion media for the best current biotechnological performances found in the literature do not exceed about $70 \mathrm{~g} / \mathrm{L}[6,14]$. For short chain carboxylic acids in dilute streams such as 3-HP, their hydrophilic character prevents their direct recovery in an organic solvent and a reagent is needed in the organic phase to trap the compound in a rather hydrophobic complex. In the case of hydrophilic carboxylic acids, these reagents can be hydrophobic basic molecules being able to interact with acidic groups [15]. Among such molecules, long chained aliphatic amines have been widely studied for a large set of carboxylic acids, such as 
hydroxycarboxylic acids like citric [16-18], glycolic [19,20], malic [21,22] and tartaric [23-26] acids, C3 monocarboxylic acids like acrylic [27], propionic [28-31] and pyruvic [32-34] acids and even lactic acid, an $\alpha$-hydroxylated C3 monocarboxylic acid (positional isomer of 3-HP) [22,23,35].

Amine basicity, steric hindrance and water solubility are relevant parameters and have an influence on extraction performances. For example, Kyuchoukov and Yankov [36] tested several amines for the extraction of lactic acid and their results show that, when amines are used in oleyl alcohol, extraction yields decrease when the steric hindrance of the amines increases. The contrary is observed when amines are used without oleyl alcohol as the active diluent. Kaur and Elst [37] studied a wide range of amines and diluents for the extraction of itaconic acid. For all the diluents tested, they found that short chain amines (tributylamine, $\mathrm{N}, \mathrm{N}$-dimethyloctylamine) and primary amines ( $n$-octylamine) had the lowest performances. On the contrary, long chain secondary and tertiary amines proved to be very efficient with very high extraction yields, probably due to their higher basicity and very low solubility in water. Secondary amines (di-n-octylamine) had better performances than tertiary amines (tri-n-octylamine) [37], and this could be explained by the lesser extent of the steric hindrance around the reactive amine group, their higher basicity and higher density of amine groups. Similar results were found in a previous study which also demonstrated that primary amines were not to be used in reactive extraction due to moderate extraction efficiency, high water solubility and high interfacial activity causing emulsion [38].

The structure of the aliphatic amines is crucial for their role as extractants, but they cannot be used alone, due to their poor solvation ability and sometimes high viscosity [39]. Consequently, they are often used in mixture with organic solvents to increase their extraction performances. Diluents can be divided into two types: active and inert. Active diluents have chemically active functional groups such as hydroxyl or carbonyl groups that are able to interact with the amphiphilic acid-base complex through hydrogen bonds and dipole-dipole interactions $[15,23]$. Inert diluents such as hydrocarbons that cannot interact with diluted molecules show lower efficiency since they are not able to stabilize 
hydrophilic compounds in the organic phase. Solvent polarity decrease, e.g. when the length of the alkyl chain increases, tends to reduce the extraction efficiency and so does the steric hindrance around the active group. For example, secondary alcohols have lower solvation capacity than their primary isomers $[37,40]$.

Apart from the effects of amines and diluents' characteristics, the acid hydrophobicity [19] and acidity [39] are key factors to evaluate the degree of extraction: the more hydrophobic and acidic the extracted acid, the higher the extraction yield [41]. Differences in extraction yields even exist when comparing very similar acids like the positional isomers 3-hydroxypropionic acid and 2hydroxypropionic acid (lactic acid) [42]. Moreover, hydrophilic carboxylic acids being polar, they tend to bind together in apolar environments such as organic phases. It is known for example that they can form dimers, trimers, and so on $[23,39]$. This phenomenon is less likely to occur in more polar active diluents. In particular, protic diluents like alcohols or chloroform are known to prevent such phenomena because of their $\mathrm{H}$-bond donor ability. The competition between the acid and the diluent to form $\mathrm{H}$-bonds with free or complexed acid molecules tends to favor acid extraction through free and complexed acid monomers [39]. All the characteristics of the compounds found in these systems play an important role on the mechanisms of extraction.

Considering all these aspects, should be preferred for 3-HP extraction a water insoluble amine (high molecular weight) providing a high density of non-hindered reactive amine groups (low molecular weight). The optimum stays in the tertiary $\mathrm{C} 8-\mathrm{C} 10$ amines range [43]. Therefore, we selected tri-noctylamine (TOA) to perform this study and investigated several diluents according to their physicochemical properties.

Since the purpose of an ISPR strategy is to keep the concentration of a product low to limit inhibition, in this study, 3-HP concentration will cover a rather dilute range of 0.0028 to $0.56 \mathrm{~mol} / \mathrm{L}(0.25$ to 50 $\mathrm{g} / \mathrm{L})$. The study focuses on phenomena occurring at low concentrations and related mechanisms such as the presence of impurities coming from the extractant phase. 
Reaction 1 describes the acid partitioning between the aqueous and organic phases:

$$
A H_{a q} \rightleftharpoons A H_{\text {org }} \quad(\text { reaction } 1)
$$

\subsubsection{Reactive extraction}

The formation of acid-amine complexes is the major reaction involved in acid recovery from aqueous phase. In an aqueous phase, acids and bases can react together through reversible reactions to give the corresponding solvated free conjugated bases and acids. In an organic phase, the weak polarity and dielectric constant can prevent species from forming the corresponding solvated free ions and the acidic and basic molecules can stay bound to each other through acid-base interactions. These interactions can consist in $\mathrm{H}$-bondings and/or ion pair formation according to the polarity of the solvent and the strength of the acid-base interactions. As a general scheme, several acid and amine molecules can form aggregates of different stoichiometries [23]. The acid-amine complex formation can be described by the reaction 2 :

$$
p A H_{a q}+q R_{3} N_{\text {org }} \rightleftharpoons\left[(A H)_{p}\left(R_{3} N\right)_{q}\right]_{o r g} \quad \text { (reaction 2) }
$$

\subsection{Chemicals}

\subsubsection{Commercial products}

Solutions of 3-hydroxypropionic acid were prepared by diluting a commercial product $(28.1 \% \mathrm{wt}$ solution in water) from TCl Europe, Zwijndrecht, Belgium. The organic phase consisted in tri-noctylamine (TOA, $98 \%$ purity) diluted either in $n$-hexanol ( $99 \%$ purity), $n$-octanol ( $99 \%$ purity), $n$ decanol ( $99 \%$ purity), $n$-dodecanol ( $98 \%$ purity), ethyl octanoate ( $98 \%$ purity), butyl hexanoate ( $98 \%$ purity), $n$-hexane (99\% purity), $n$-decane (99\% purity), $n$-dodecane ( $99 \%$ purity) from Sigma-aldrich, 
Saint-Louis, the USA, oleyl alcohol ( $82.4 \%$ purity, with impurities consisting mainly in other fatty alcohols like linoleyl and stearyl alcohols $[44,45]$ ) from TCI Europe or refined sunflower oil (mainly triglycerides of oleic and linoleic acids, Lesieur, France).

In order to further investigate the influence of TOA purity on extraction efficiency, three different organic phases have been made with three different TOA purities. Two TOA solutions were purchased from the same commercial reference but had two lot numbers with different purity levels corresponding to the variations of production quality: $98.1 \%$, solution 1 , and $99.6 \%$, solution 2 , according to the certificates of analysis given by the supplier (Sigma-Aldrich). Solution 3 was obtained by purification of solution 2 as detailed below.

\subsubsection{TOA purification}

Purified TOA (solution 3) was produced as follows. The 99.6\% TOA was washed using same volumes of $\mathrm{H}_{2} \mathrm{SO}_{4} 0.1 \mathrm{M}$. After centrifugation, 3 homogeneous phases were observed. Only the top phase was recovered and further washed with $\mathrm{NaOH} 0.3 \mathrm{M}$. Indeed, the phase in-between is suspected to be loaded in acid-amine complexes [23] and to be sure that a maximum of impurities were removed from the TOA phase, only the top phase was recovered. These operations were repeated twice and the last TOA top phase was finally washed with deionized water. The $\mathrm{pH}$ of the final aqueous phase has been checked to be neutral, proving that no inorganic salts were left in purified TOA and this latter is called solution 3.

\subsection{Experiments}

Several experiments of reactive liquid-liquid extractions were performed for different initial concentrations of TOA and 3-HP. Unless specified, TOA of solution 2 (99.6\% purity) was used. For each extraction, $10 \mathrm{~mL}$ of the aqueous phase and $10 \mathrm{~mL}$ of the organic phase were mixed in centrifuge tubes which were then manually shaken for 3 minutes. The stable emulsion formed was then left at $25^{\circ} \mathrm{C}$ for one day before being shaken again for 3 minutes and centrifuged at $15557 \mathrm{~g}$ for 
11 hour. Once the aqueous phase recovered, it was analyzed using High Performance Liquid

2 Chromatography (HPLC) and the extraction yield was calculated as follows:

$$
Y=\frac{[A H]_{H P L C}^{i n i}-[A H]_{H P L C}^{e q}}{[A H]_{H P L C}^{i n i}}
$$

3 with $[A H]_{H P L C}^{i n i}$ being the total initial acid concentration in the aqueous phase according to HPLC 4 analysis and $[A H]_{H P L C}^{e q}$ the same at equilibrium.

$5 \mathrm{pH}$ of the resulting aqueous phases was measured and compared to the theoretical $\mathrm{pH}$ value, based 6 on the 3-HP dissociation (reaction 3) and calculated as follows:

$$
\begin{gathered}
A H \rightleftharpoons A^{-}+H^{+} \quad K_{A}^{A H}=3.0910^{-5}[46] \quad \text { (reaction 3) } \\
p H_{t h}=-\log \left(\frac{-K_{A}^{A H}+\sqrt{\left(K_{A}^{A H}\right)^{2}+4 K_{A}^{A H}[A H]_{H P L C}}}{2}\right)
\end{gathered}
$$

7 All the extractions were made in duplicates. For some experiments, organic phases have been back

8 9 extracted with $\mathrm{NaOH}$ solutions (0.1-0.5 M) in order to confirm that mass balance was satisfied within $3 \%$ or less.

Experiments were centered on $0.011 \mathrm{~mol} / \mathrm{L}(1 \mathrm{~g} / \mathrm{L}) 3-\mathrm{HP}$ and the optimal extractant concentration for this condition $(0.46 \mathrm{~mol} / \mathrm{L}=20 \% \mathrm{v} / \mathrm{v}$ TOA) [42]. The initial acid concentration ranged from 0.0028 $\mathrm{mol} / \mathrm{L}$ to $0.56 \mathrm{~mol} / \mathrm{L}(0.25$ to $50 \mathrm{~g} / \mathrm{L})$ for $0.46 \mathrm{~mol} / \mathrm{L}(20 \% \mathrm{v} / \mathrm{v})$ TOA in order to clearly observe limiting factors at low concentrations while having good quantification results in HPLC. Concerning the initial concentrations of amines, the whole range from 0 to $100 \% \mathrm{v} / \mathrm{v}(0-2.3 \mathrm{~mol} / \mathrm{L})$ was studied with steps of $10 \% \mathrm{v} / \mathrm{v}(0.23 \mathrm{~mol} / \mathrm{L})$ for $0.011 \mathrm{~mol} / \mathrm{L}(1 \mathrm{~g} / \mathrm{L}) 3-\mathrm{HP}$.

\subsection{Analytical methods}

The 3-HP concentration in aqueous phases was determined using HPLC containing an Aminex HPX87 $\mathrm{H} \mathrm{H}^{+}$exchange column (300x7.8 mm, Biorad, USA) and an $\mathrm{H}^{+}$Micro-Guard column (30 mmx4.6mm, 
Biorad, USA). The mobile phase consisted in a $0.01 \mathrm{~N} \mathrm{H}_{2} \mathrm{SO}_{4}$ solution circulating at a flowrate of 0.6 $\mathrm{mL} / \mathrm{min}$ and the column temperature was set to $50^{\circ} \mathrm{C}$. An internal standard consisting in $10 \mathrm{~g} / \mathrm{L}$ citric acid in water was added $(50 \% \mathrm{v} / \mathrm{v})$ to the samples and $20 \mu \mathrm{L}$ of each sample were used for injection. Signals were obtained using a UV detector with the specific wavelength of $210 \mathrm{~nm}$ for acids. The overall HPLC analysis uncertainty, defined as the coefficient of variation of the internal standard peak area, was evaluated to $1 \%$.

Impurities identification and titration in the aqueous phase were performed using Ultra High Performance Liquid Chromatography coupled with High Resolution Mass Spectroscopy (UHPLCHRMS). Separations were performed using a Hypersil Gold C18 column (50X2.1 mM; $1.9 \mu \mathrm{m}$ particle size; Thermo Fisher Scientific, USA) with an Ultimate 3000 pump and Thermo 3000 RS autosampler (Thermo Fisher Scientific, USA). The oven temperature was set to $25^{\circ} \mathrm{C}$. The mobile phase was a mixture of LC/MS grade acetonitrile and water loaded with $0.1 \%$ formic acid (Optima, Thermo Fischer Scientific, USA) flowing at $250 \mu \mathrm{L} / \mathrm{min}$. In a run, it first consisted in $2 \%$ acetonitrile for 4 minutes. Then a gradient was applied to reach $98 \%$ acetonitrile in 6 minutes and the mixture was then stabilized at $98 \%$ acetonitrile for 5 minutes. The mobile phase was finally set back to initial conditions ( $2 \%$ acetonitrile) with a 2 minutes gradient.

Samples were diluted 100-fold in water (Optima LC/MS grade, Thermo Fischer Scientific, USA) and filtered before assay with syringe filters (nylon membrane, $0.2 \mu \mathrm{m}$ porosity and $13 \mathrm{~mm}$ diameter, Merck Millipore, USA).

MS analysis was carried out with a Q-EXACTIVE Orbitrap mass spectrometer (Thermo Fisher Scientific, USA) in positive mode with a Heated ElectroSpray lonization (HESI) probe using a high resolution full scan. The MS resolution was 70000 in a full MS mass range $(\mathrm{m} / \mathrm{z})$ from 50 to $700 \mathrm{AMU}$. The ion transfer tube and vaporizer temperatures were set to $300^{\circ} \mathrm{C}$. The electrospray voltage was set to $3 \mathrm{kV}$ and the sheath, auxiliary and sweep gas (nitrogen) flow rates were set to 35,10 and 0 arbitrary units, respectively. 
2 Technologies (California, USA).

$3 \mathrm{pH}$ measurements were obtained from a SevenCompact pHmeter equipped with the Inlab Micro Pro-

$4 \quad$ ISM combined pH electrode with temperature probe (Mettler Toledo, Switzerland).

5 Water concentration in the organic phase was determined using Karl-Fischer method with a 756 KF Coulometer (Metrohm, Switzerland). Methanol was the solvent for titration. Organic phase samples were analyzed in triplicate.

Statistical significance of differences between data was assessed using ANOVA tests at 0.05 level.

\section{Results and discussion}

\subsection{Solvents screening}

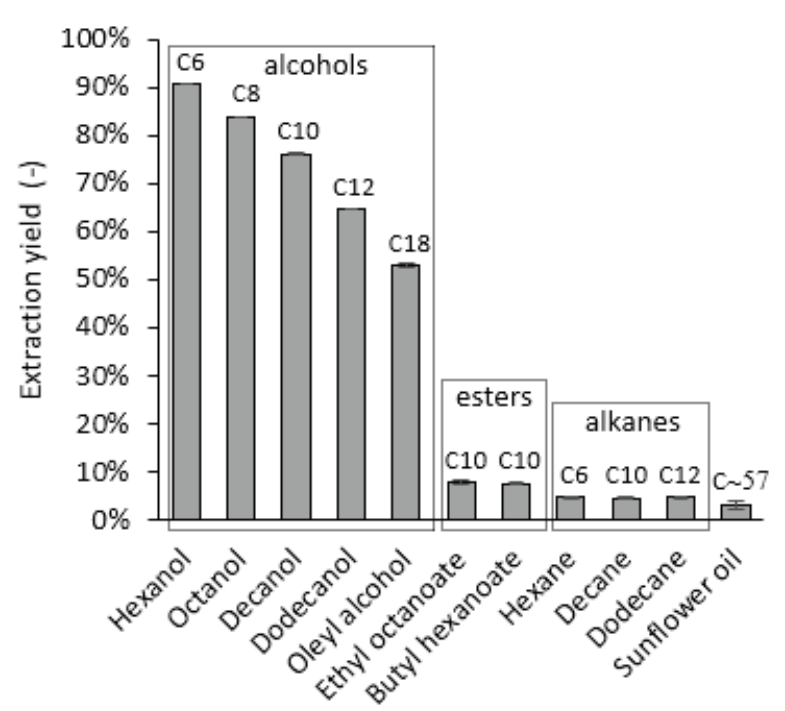

Figure 1: Extraction yields for different solvents with $0.46 \mathrm{~mol} / \mathrm{L}$ of TOA (20\% v/v) and $0.011 \mathrm{~mol} / \mathrm{L}$ of 3-HP (1 $g / L)$. Error bars represent standard deviations ( $n=2)$.

14 First, a set of 11 solvents were selected for a screening regarding the reactive extraction of 0.011 $\mathrm{mol} / \mathrm{L}(1 \mathrm{~g} / \mathrm{L})$ of $3-\mathrm{HP}$ in aqueous phase using $0.46 \mathrm{~mol} / \mathrm{L}$ of purified TOA $(20 \% \mathrm{v} / \mathrm{v})$ in the organic phase. Figure 1 provides the extraction yields for these solvents. 
efficiently. $n$-hexane, $n$-decane and $n$-dodecane having the same values of relevant parameters (dipole moment, relative permittivity and $\mathrm{H}$-bond ability), all provide the same efficiency as expected ( $5 \%$ yield). The same observations apply to the esters: both esters having the same relevant properties, they show equivalent performances (around $8 \%$ yield). This slightly, but significantly higher yield (ANOVA test with $p<0.02$ ), can be explained by the slightly higher polarity of the two esters compared to the three alkanes, which makes them a bit more active diluents. It is also interesting to compare esters and alcohols with similar polarities but different $\mathrm{H}$-bond abilities like butylhexanoate and ethyloctanoate vs. oleyl alcohol and $n$-dodecanol. A much higher yield is obtained for both alcohols ( 7 times higher for oleyl alcohol than for the esters), which leads to the conclusion that the $\mathrm{H}$-bond donor character of the solvent plays a key role, implying that alcohols stabilize the reactive system through $\mathrm{H}$-bonding interactions. Ricker [43] suggests that the acidic hydrogen of the carboxylic acid being involved in the acid-amine bond, carboxyl becomes a strictly acceptor group. This would explain such a difference between $\mathrm{H}$-bond donors and acceptors as solvents of otherwise similar polarities. Similar results in the literature confirm the importance of the solvent polarity and specific $\mathrm{H}$-bond donor character to favor the complex formation and increase the extraction yields $[23,31,37,39]$.

Based on these results, $n$-decanol and oleyl alcohol were chosen for further investigations. $n$-hexanol and octanol were ruled out due to their excessive solubility in water that is expected to be toxic for microorganisms under integrated extractive bioconversion (ISPR) [51,52]. According to the literature review, some biocompatible vegetable oils, thanks to their low polarity and solubility in water, have been shown to be quite efficient for the removal of similar acids (propionic, pyruvic, lactic) from aqueous phases [47-49]. But in our present results, sunflower oil was found to be inefficient for 3-HP extraction with TOA (less than 7\% yield) whatever the proportions used because of its weak solvation properties.

\subsection{Physical extraction}


1

2

3

For physical extraction experiments, concentration of 3-HP were varied from 0.0028 to $0.56 \mathrm{~mol} / \mathrm{L}$ ( 0.25 to $50 \mathrm{~g} / \mathrm{L}$ ) with no TOA in the organic phase. In $n$-decanol, a linear dependence $\left(R^{2}=0.96\right)$ of the equilibrium acid concentration in the organic phase with respect to that in the aqueous phase was found (results not shown). The slope, i.e. the partition coefficient (defined as the ratio of the molar concentrations at equilibrium), was evaluated to $0.020 \pm 0.001$ by linear regression, meaning that physical extraction yield was around $2 \%$. This is in line with Kertes and King's statement that the acid partition coefficient is independent on its concentration in the case of extraction using alcohols [15]. In oleyl alcohol, 3-HP partitioning was not detectable. Physical extraction yields were thus too low for practical purposes, confirming that the efficient liquid-liquid extraction of 3-HP needs to be driven by a chemical reaction.

\subsection{Effects of initial amine concentration}

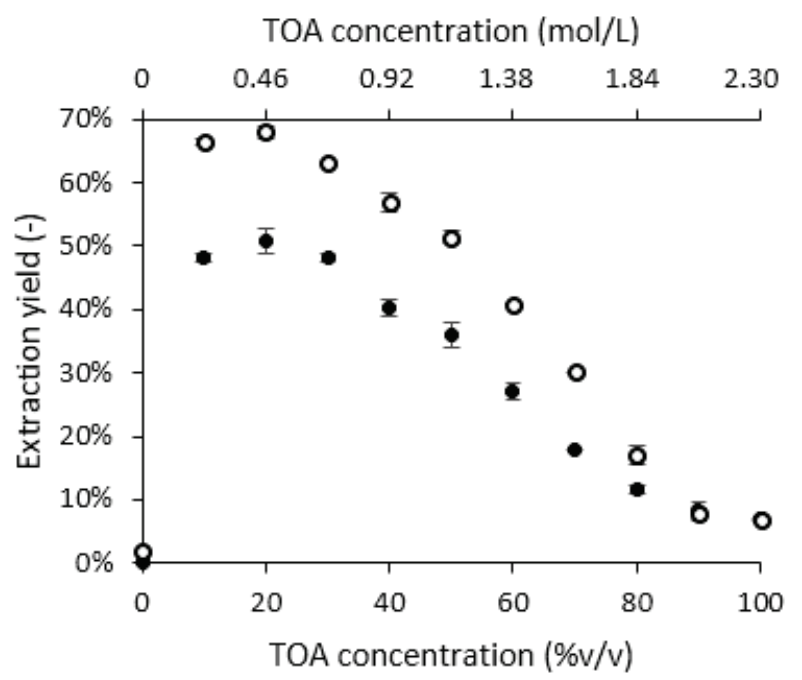

Figure 2: Extractions yields as a function of TOA concentration in decanol (open circles) and oleyl alcohol (filled circles), with $0.011 \mathrm{~mol} / \mathrm{L}(1 \mathrm{~g} / \mathrm{L}$ ) of 3-HP initially. Error bars represent standard deviations ( $n=2)$.

Figure 2 shows the extraction yield as a function of initial TOA concentration in the organic phase for $0.011 \mathrm{~mol} / \mathrm{L}(1 \mathrm{~g} / \mathrm{L})$ of 3-HP initially in water, with $n$-decanol and oleyl alcohol as solvents. For both solvents, a bell-shaped profile can be observed. This profile illutrates the synergistic effect between TOA and these active diluents and thus the major role of the solvent. When used alone, neither TOA nor the solvents are able to extract $3-\mathrm{HP}$ efficiently (less than $10 \%$ yield). However, a strong 
synergistic effect was observed when TOA was mixed with an active diluent. Indeed, TOA has poor solvation abilities to accumulate complexes whereas $n$-decanol and oleyl alcohol are not hydrophilic enough to extract such a hydrophilic compound in substantial proportions. When the amine and the solvent are used together, new hydrophobic properties of the complexed acid and new solvation abilities of the organic phase improve the extraction efficiency.

(1)
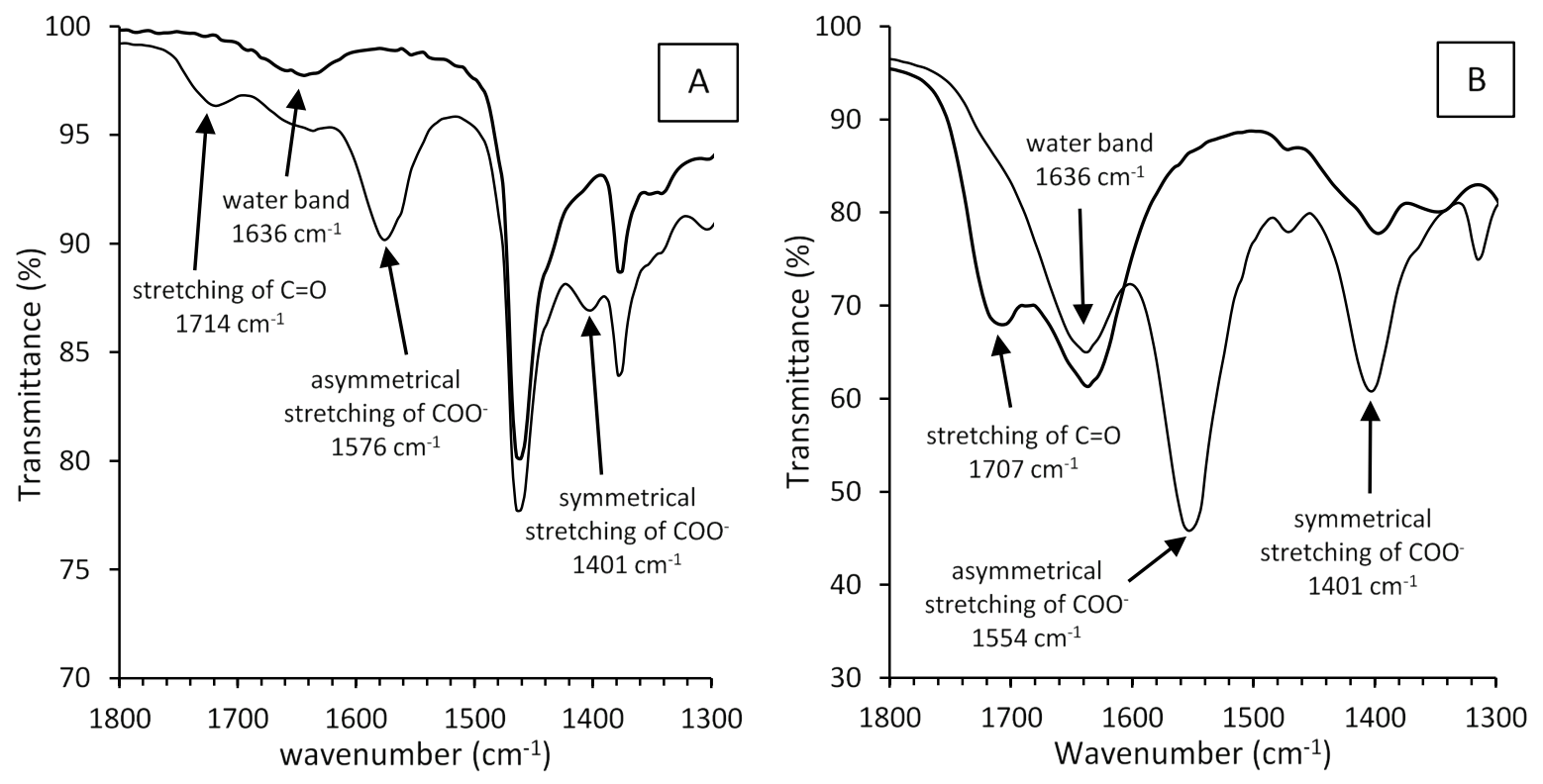

Figure 3: IR spectra of organic phases after 3-HP extraction $(53 \mathrm{~g} / \mathrm{L}$ in the organic phase, bold line) and after simple water contact (thin line) (A) and IR spectra of commercial aqueous phases of 3-HP before (bold line) and after (thin line) neutralization with $\mathrm{NaOH}(\mathrm{B})$

Figure 3 provides IR spectra obtained from two different solutions: Figure 3A shows organic phases

consisting in $20 \% \mathrm{v} / \mathrm{v}$ TOA in $n$-decanol and Figure 3B shows aqueous phases of the 3 -HP commercial

solution for comparison. When TOA is present in the organic phase (Figure 7A), characteristic infrared bands between 1300 and $1800 \mathrm{~cm}^{-1}$ prove the existence of a delocalized carboxylate group in the organic phase demonstrating strong interactions between the acidic proton of 3-HP and the amine leading to the formation of an ion pair. This observation is related to the formation of complexes involving 3-HP bonded to TOA. The fatty amine provides hydrophobic properties to the species formed, enabling a favorable distribution of the acid towards the organic phase. However, the anion, being such a polar part, needs a polar counterparts in the medium to be stabilized. 
3 As a consequence, the extraction yield of 3-HP decreases at high amine concentrations, a behavior

4 that aligns well with reported data for acetic [43], lactic [36,56], malonic [57], propionic [30], succinic

$5 \quad[23,57]$ and tartaric [25] acids in active diluents. This behavior is not observed in the case of inert

6 diluents in which the yield increases along with the amines concentration [23]. The greatest extent of

7 extraction of $3-\mathrm{HP}$ is reached around $0.46 \mathrm{~mol} / \mathrm{L}(20 \% \mathrm{v} / \mathrm{v})$ TOA in both active diluents at $0.011 \mathrm{~mol} / \mathrm{L}$

$8 \quad(1 \mathrm{~g} / \mathrm{L})$ of 3 -HP initially with $68 \%$ and $51 \%$ yields for $n$-decanol and oleyl alcohol respectively. The

9 maximum of the extraction yield corresponds to the optimal composition of the extracting phase.

10

11

12

13

14

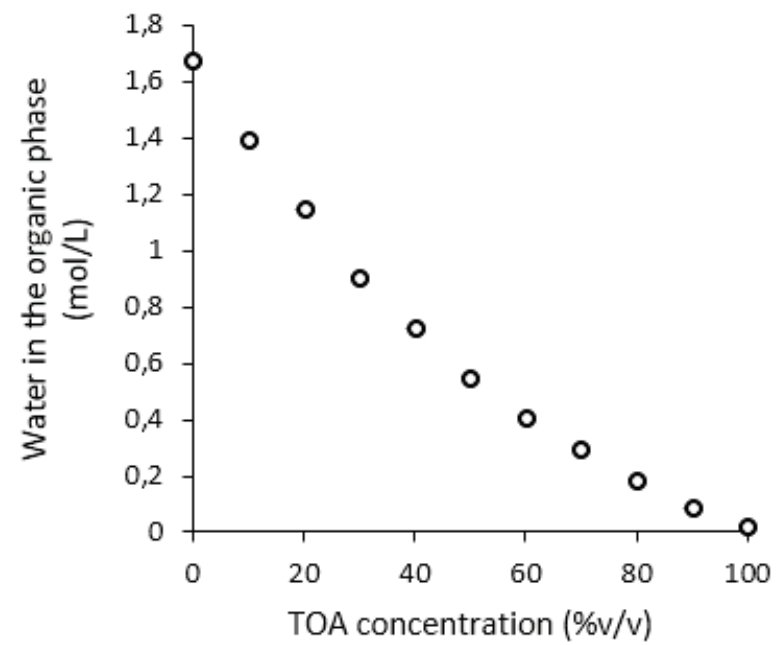

Figure 4: Water solubility in the organic phase as a function of TOA concentration $(0-2.3 \mathrm{~mol} / \mathrm{L})$ in decanol at $25^{\circ} \mathrm{C}$. Error bars represent standard deviations $(n=3)$ and are masked by the symbols.

Moreover, water solubility appears to play a crucial role. As shown in Figure 4, the more the organic phase is loaded with TOA, the less water is soluble, water being practically insoluble in TOA. Increasing the amount of TOA leads to a decrease of water content in the organic phase which could lead to a lesser stabilization of the complex and hence a lesser extraction efficiency. Tamada et al [57] reported that the amount of acid extracted and the stoichiometry of the complex in the organic phase depended on the water content in the organic phase. The amount of water soluble in the organic phase is supposed to stabilize the hydrophilic part of the complex in a rather apolar 
environment. Increasing the concentration of alcohol in the organic phase increases the water solubility and therefore the solvation effect of alcohols could be in fact partially due to the solvation of water. The balance between the respective contributions in complex stabilisation cannot be assessed based on the present results because the amounts of water and alcohol are correlated.

\subsection{Effects of initial acid concentration}

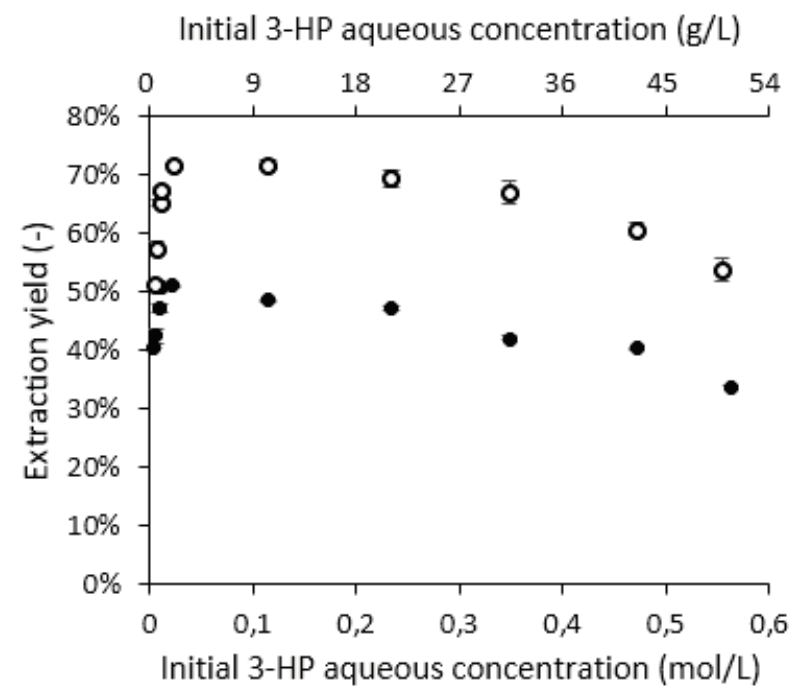

Figure 5: Extraction yields in decanol (open circles) and oleyl alcohol (filled circles) with $0.46 \mathrm{~mol} / \mathrm{L}$ TOA (20\% $v / v$ ) as a function of initial acid concentration. Error bars represent standard deviations ( $n=2)$.

Concerning the influence of the acid concentration, Figure 5 shows that the plot of the extraction yield against initial acid concentration is not monotonic. If we consider only the partitioning of the acid and the complex formation, such a profile is not expected. Indeed, the more diluted is the acid and the more in excess are the amines; this should lead to a higher extent of reaction 2 (acid-amine complex formation) and therefore the increase of extraction yield with the decrease of 3-HP concentration. This behavior was indeed observed for initial acid concentration levels between 0.11 and $0.56 \mathrm{~mol} / \mathrm{L}(10-50 \mathrm{~g} / \mathrm{L})$. But for the weakest concentration levels, a sharp decrease is observed and other phenomena are needed to explain such results. For example, in oleyl alcohol the extraction yield decreased from $51 \%$ to $40 \%$ and in $n$-decanol from $72 \%$ to $51 \%$ between 0.023 and $0.0041 \mathrm{~mol} / \mathrm{L}(2-0.4 \mathrm{~g} / \mathrm{L})$ of 3-HP initially. Deeper investigations on $\mathrm{pH}$ effects were undertaken in the case of $n$-decanol to understand these phenomena (section 3.5.). 
3-HP in the organic phase after extraction

$(\mathrm{g} / \mathrm{L})$

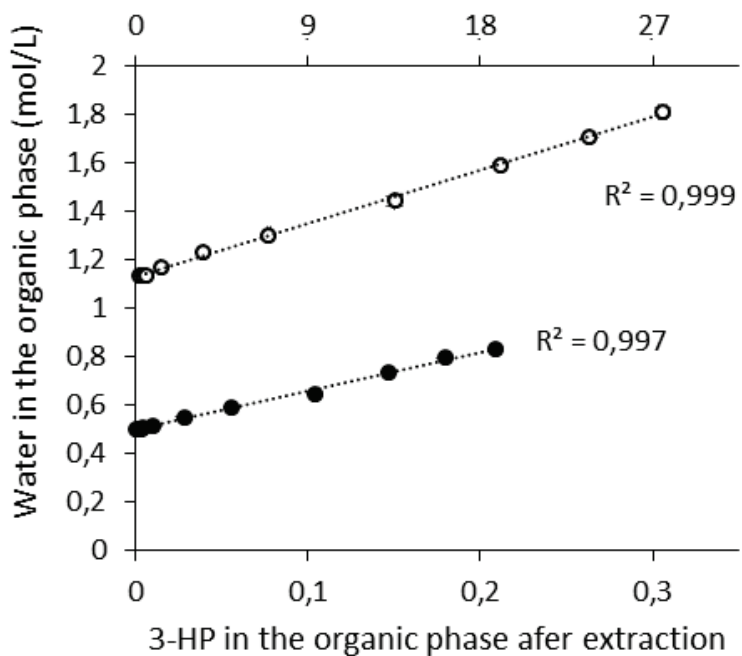

( $\mathrm{mol} / \mathrm{L})$

Figure 6: water co-extraction in decanol (open circles) and oleyl alcohol (filled circles) with 0.46 mol/L TOA (20\% $v / v)$ as a function of the acid concentration in the organic phase after extraction. Error bars represent standard deviations $(n=3)$ and are masked by the symbols.

5 A further look at the water content of the organic phase after extraction proves that water is extracted in the organic phase jointly with the acid (Figure 6). Indeed, the more acid extracted, the more water in the organic phase. Indeed, water concentration reached higher amounts than its solubility in $n$-decanol with $20 \%$ v/v TOA (1.14 mol $\mathrm{H}_{2} \mathrm{O} / \mathrm{L}$, Figure 4 ) and in oleyl alcohol with $20 \% \mathrm{v} / \mathrm{v}$ TOA $\left(0.50 \mathrm{~mol} \mathrm{H}_{2} \mathrm{O} / \mathrm{L}\right)$. Figure 6 shows that the amount of water in the organic phase varies linearly with the acid concentration. This tends to prove that, in the range studied, each 3-HP molecule carries the same average number of water molecules in the organic phase. This hydration number (given by the slopes of the regression lines in Figure 6) is around 2 for $n$-decanol and oleyl alcohol as solvents. This tendency of 3-HP to carry water molecules while being extracted in the organic phase could also partly explain why the extraction yield was very low with alkanes (section 3.1). 
3

Table 2: amount of amines $(O A+D O A)$ found in the aqueous phase after extraction and associated measured $\left(p H_{e q}\right)$ and calculated $\left(\mathrm{pH}_{t h}\right.$ and $\left.\mathrm{pH}_{\text {th.OA }}\right) \mathrm{pH}$, as a function of initial 3-HP and TOA concentrations, for solutions 1 ( $98.1 \%$ of TOA purity), 2 (99.6\% of TOA purity) and 3 (>99.6\%: purified TOA)

\begin{tabular}{|c|c|c|c|c|c|}
\hline \multicolumn{6}{|c|}{ Solution 1 (TOA 98.1\%) } \\
\hline $\begin{array}{l}A H]_{\text {ini }} \\
(\mathrm{mol} / \mathrm{L})\end{array}$ & $\begin{array}{c}\text { TOA }]_{\text {ini }} \\
(\mathrm{mol} / \mathrm{L})\end{array}$ & $\begin{array}{c}{[O A]_{L C M S}} \\
(\mathrm{mmol} / \mathrm{L})\end{array}$ & $p H_{e q}$ & $\overline{p H_{t h}}$ & $p H_{t h, O A}$ \\
\hline 0.0028 & 0.46 & 2.0 & 5.4 & 3.6 & 5.1 \\
\hline 0.011 & 0.46 & 2.6 & 4.6 & 3.4 & 4.5 \\
\hline 0.029 & 0.46 & 2.8 & 4.1 & 3.3 & 4.1 \\
\hline 0.058 & 0.46 & 2.7 & 3.8 & 3.1 & 3.8 \\
\hline 0.10 & 0.46 & 2.5 & 3.5 & 3.0 & 3.5 \\
\hline 0.21 & 0.46 & 2.9 & 3.2 & 2.9 & 3.3 \\
\hline 0.31 & 0.46 & 2.8 & 3.0 & 2.8 & 3.1 \\
\hline 0.50 & 0.46 & 2.8 & 2.8 & 2.6 & 2.8 \\
\hline 0.011 & 0.23 & 1.4 & 4.2 & 3.4 & 4.2 \\
\hline 0.011 & 0.69 & 3.6 & 4.9 & 3.4 & 4.6 \\
\hline 0.011 & 0.91 & 4.6 & 5.0 & 3.3 & 4.7 \\
\hline 0.011 & 1.4 & 6.4 & 5.2 & 3.3 & 4.9 \\
\hline 0.011 & 1.8 & 8.5 & 5.4 & 3.3 & 5.3 \\
\hline 0.011 & 2.1 & 8.7 & 5.4 & 3.3 & 5.3 \\
\hline \multicolumn{6}{|c|}{ Solution 2 (TOA 99.6\%) } \\
\hline 0.0041 & 0.46 & 1.0 & 4.8 & 3.6 & 4.5 \\
\hline 0.011 & 0.46 & 1.2 & 4.3 & 3.5 & 4.2 \\
\hline 0.023 & 0.46 & 1.2 & 4.1 & 3.4 & 3.9 \\
\hline 0.11 & 0.46 & 1.2 & 3.4 & 3.0 & 3.3 \\
\hline 0.23 & 0.46 & 1.2 & 3.2 & 2.8 & 3.0 \\
\hline 0.35 & 0.46 & 1.2 & 3.2 & 2.7 & 2.9 \\
\hline 0.55 & 0.46 & 1.3 & 2.9 & 2.6 & 2.7 \\
\hline 0.011 & 0.23 & 0.54 & 4.1 & 3.5 & 3.8 \\
\hline 0.011 & 0.69 & 1.5 & 4.5 & 3.5 & 4.3 \\
\hline 0.011 & 0.91 & 2.3 & 4.6 & 3.4 & 4.5 \\
\hline 0.011 & 1.4 & 3.4 & 4.5 & 3.4 & 4.5 \\
\hline 0.011 & 1.8 & 4.9 & 4.5 & 3.3 & 4.5 \\
\hline 0.011 & 2.1 & 5.4 & 4.5 & 3.3 & 4.5 \\
\hline \multicolumn{6}{|c|}{ Solution 3 (purified TOA) } \\
\hline 0.0027 & 0.46 & 0.065 & 4.1 & 3.9 & 4.0 \\
\hline 0.011 & 0.46 & 0.039 & 3.7 & 3.6 & 3.6 \\
\hline 0.021 & 0.46 & 0.048 & 3.5 & 3.4 & 3.5 \\
\hline 0.053 & 0.46 & 0.040 & 3.2 & 3.2 & 3.2 \\
\hline 0.11 & 0.46 & 0.039 & 3.0 & 3.0 & 3.0 \\
\hline 0.21 & 0.46 & 0.029 & 2.8 & 2.9 & 2.9 \\
\hline 0.32 & 0.46 & 0.034 & 2.7 & 2.7 & 2.7 \\
\hline 0.53 & 0.46 & 0.031 & 2.5 & 2.6 & 2.6 \\
\hline 0.011 & 0.23 & 0.053 & 3.5 & 3.5 & 3.6 \\
\hline 0.011 & 0.69 & 0.062 & 3.6 & 3.6 & 3.6 \\
\hline 0.011 & 0.91 & 0.134 & 3.6 & 3.6 & 3.6 \\
\hline 0.011 & 1.4 & 0.191 & 3.6 & 3.5 & 3.6 \\
\hline 0.011 & 1.8 & 0.319 & 3.4 & 3.4 & 3.5 \\
\hline 0.011 & 2.1 & 0.318 & 3.4 & 3.3 & 3.4 \\
\hline
\end{tabular}

6

$7 \mathrm{pH}$ of aqueous solutions were measured for after extraction and compared to the calculated values.

Results are shown in Table 2 (solution 2). Considering the $\mathrm{pH}$ at the equilibrium in the aqueous phase 
$1\left(p H_{e q}\right)$, it appears that for the lowest acid concentrations the experimental data are above the

2 calculated values from acid concentrations at equilibrium alone $\left(p H_{t h}\right.$, reaction 3 , equation 2$)$. This means that higher amounts of 3-HP molecules are deprotonated compared to what is expected with only 3-HP in water. When performing $\mathrm{pH}$ titrations of aqueous phases after acetic acid extraction by TOA in chloroform, Wardell and King [58] also reported $\mathrm{pH}$ deviations. They attributed this phenomenon to the transfer of tri- $n$-octylamine in the aqueous phase in the presence of acid. The same was found for lactic acid extraction at low concentration with Alamine 336 [59]. However, Ricker [43] demonstrated that, even in $10 \%$ wt acetic acid in water, TOA solubility would not exceed $10 \mathrm{ppm}$ (i.e. $<310^{-5} \mathrm{~mol} / \mathrm{L}$ ) and suggested that $\mathrm{pH}$ deviation may have been due to impurities in commercial products like primary and secondary amines, lower-molecular-weight tertiary amines and starting materials for the amine synthesis.

When sodium hydroxide was added to our aqueous samples after extraction, a condensation of organic species occurred and the solution became cloudy as already reported by some authors $[57,58]$. On the contrary, pure distilled water contacted with commercial TOA solution resulted in a neutral $\mathrm{pH}$ without any noticeable visual change when $\mathrm{NaOH}$ was added. This illustrates the fact that impurities are extracted in the aqueous phase under protonated form through reactive extraction with acidic species (see reaction 4) and that their partitioning as neutral forms can be neglected:

$$
A H_{a q}+B_{o r g} \rightleftharpoons A_{a q}^{-}+B H_{a q}^{+} \quad(\text { reaction } 4)
$$

3.5.2. Identification of TOA impurities

Aqueous samples after extraction were analyzed with mass spectroscopy. Two main peaks appeared at $m / z=130$ and $m / z=242$ corresponding to both peaks of protonated $n$-octylamine $(129+1=130$ $\mathrm{g} / \mathrm{mol})$ and protonated di- -octylamine $(241+1=242 \mathrm{~g} / \mathrm{mol})$. Commercial samples of $n$-octylamine (OA) and di-n-octylamine (DOA) were also analyzed to confirm species identification. Several manufacturing processes exist for the production of fatty amines like nitrile hydrogenation or alcohols amination. For example, TOA has been produced by BASF using $n$-octanol amination with 
ammonia and OA leading to impurities of around $2 \%$ DOA and $1 \%$ OA [60]. This tends to confirm the presence of these impurities in the products in our study.

When acidic species are present in the aqueous phase, these TOA impurities (OA and DOA) undergo protonation and both deprotonated acid molecules and protonated amine molecules are released in the aqueous phase increasing the $\mathrm{pH}$ (Table 2, solutions 1 and 2). This phenomenon can be neglected at high acid concentration because impurities amount remains relatively low and the protonated form of TOA is practically insoluble in water [43] so that relatively low amount of acid is neutralized in the aqueous phase. Consequently, the increase of the dissociated part of 3-HP is significant only for low concentrations and this phenomenon significantly decreases the extraction yield only for concentrations under $0.1 \mathrm{~mol} / \mathrm{L}(10 \mathrm{~g} / \mathrm{L}$, Figure 5).

Potentiometric titration with colorimetry is often used to determine extraction yields in reactive extraction with phenolphthalein as a $\mathrm{pH}$ indictor $[18,20,21,23,29,34]$. However, the usual color turning point of phenolphthalein is at $\mathrm{pH}=8.2$ [46] which means that acidic species at $\mathrm{pH}>8.2$ are not titrated. The pKa of $n$-octylammonium is 10.65 [46] which means that OA remains under its acidic form ( $n$-octylammonium) above $\mathrm{pH}=8.2$ and is not titrated. It implies that acidic species neutralized by $n$-octylamine are not taken into account in this titration method. From our results, it can be concluded that $\mathrm{pH}$ colorimetric titration is not appropriate to determine extraction yields when amines are used as extractants because it could lead to underestimated acid concentration in the aqueous phase and hence overestimating the yields, especially for low acid concentration.

\subsubsection{Influence of TOA impurities on the extraction mechanisms}

Three TOA solutions with different purity levels have been used in order to evaluate the impact of TOA impurities on the extraction process.

Analyses of aqueous phases after extraction proved that no significant TOA were released in the aqueous phases. However, OA and DOA were identified and quantified, with the former as the main 

theoretical

amine in the aqueous phase (more than $90 \%$ of total amines concentration). Hence, total amount of amines $(O A+D O A)$ in the aqueous phase is assimilated to $O A$ to simplify further interpretation. The amount of OA varied between 0.031 and $9.1 \mathrm{mmol} / \mathrm{L}$ (Table 2), depending on the following operating conditions: TOA initial concentration in the organic phase, purity of TOA and 3-HP initial concentration in the aqueous phase.

Amine transfer into the aqueous phase increases the $\mathrm{pH}$. Accordingly, an amended formula should be used to calculate the $\mathrm{pH}$ by taking into account the amines. Knowing the total concentration of amines in the aqueous phase and their dissociation constants, the equilibrium $\mathrm{pH}$ of 3 -HP solutions can then be calculated. If we consider that amines in the aqueous phase mainly consist in $\mathrm{OA}$, the $\mathrm{pH}$ calculation becomes:

$$
p H_{t h, O A}=-\log \left(\left[H^{+}\right]\right)
$$

$\left[\mathrm{H}^{+}\right]$being the physical solution of the following equation (4), based on 3-HP dissociation (reaction 3), n-octylammonium dissociation (reaction 5), water autoprotolysis (reaction 6) and the electroneutrality principle:

$$
\begin{gathered}
O A H^{+} \rightleftharpoons O A+H^{+} \quad K_{A}^{O A}=2.2410^{-11}[46] \quad(\text { reaction } 5) \\
\left.H_{2} O \rightleftharpoons H^{+}+H O^{-} \quad K_{w}=10^{-14}[46] \quad \text { (reaction } 6\right) \\
\frac{K_{A}^{A H}[A H]_{H P L C}}{\left[H^{+}\right]+K_{A}^{A H}}+\frac{K_{w}}{\left[H^{+}\right]}-\frac{\left[H^{+}\right][O A]_{L C M S}}{K_{A}^{O A}+\left[H^{+}\right]}-\left[H^{+}\right]=0
\end{gathered}
$$

As can be seen in table 2, values of $\mathrm{pH}_{\mathrm{th}, \mathrm{OA}}$ are much closer to the $\mathrm{pH}$ measured experimentally. Accordingly, the deviations observed between $\mathrm{pH}_{\mathrm{eq}}$ and $\mathrm{pH}_{\mathrm{th}}$ are directly related to the impurities in commercial TOA. Moreover, $\mathrm{pH}$ measurement can give, as a first approximation, reliable information about the amount of impurities $(\mathrm{OA})$ transferred into the aqueous phase.

Since only non-dissociated 3-HP can be extracted by TOA in the organic phase, amines transfer into the aqueous phase and the consequent increase in $\mathrm{pH}_{\text {eq }}$ reduces the amount of protonated 3-HP 
2 yield.

Initial 3-HP concentration $(\mathrm{g} / \mathrm{L})$

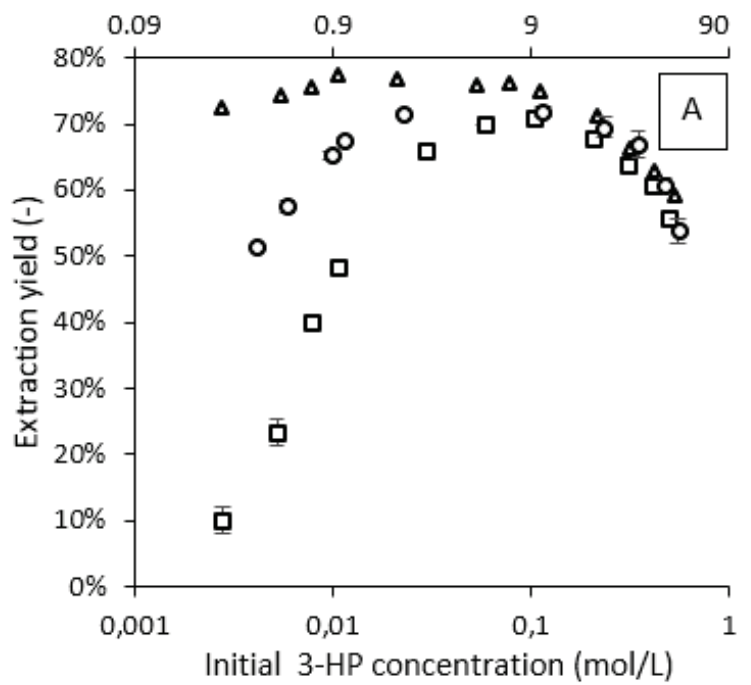

TOA concentration ( $\mathrm{mol} / \mathrm{L})$

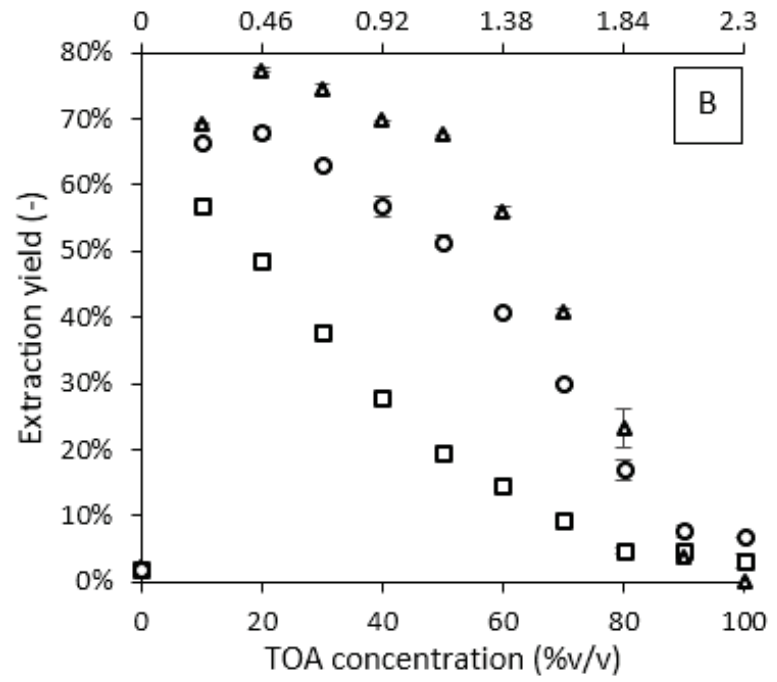

Figure 7: Extraction yields for different TOA solutions (squares: solution 1 (98.1\% purity); circles: solution 2 (99.6\% purity); triangles: solution 3 (purified TOA)) in decanol as a function of initial acid concentration at 0.46 mol/L TOA (20\% v/v) (A) and initial TOA concentration at $0.011 \mathrm{~mol} / \mathrm{L} \mathrm{3-HP} \mathrm{(1} \mathrm{g} / \mathrm{L})(B)$. Error bars represent standard deviations $(n=2)$.

Yield reduction caused by TOA impurities is illustrated in figures 5 and 7A for low acid concentrations.

In Figure $7 \mathrm{~A}$, the plot is given in logarithmic scale for initial 3-HP concentration in order to clearly observe the discrepancies for the small acid concentrations and the similarities for high acid concentrations. For a given TOA concentration in the organic phase $(0.46 \mathrm{~mol} / \mathrm{L}=20 \% \mathrm{v} / \mathrm{v})$, the three solutions provide equivalent yields at high acid concentration $(>0.11 \mathrm{~mol} / \mathrm{L}=10 \mathrm{~g} / \mathrm{L})$. This was expected since the amount of amines released in the aqueous phase is small compared to the acid concentration, and its influence on the yield becomes negligible. However, for low acid concentrations, OA and DOA impurities present in TOA solutions have a strong impact. For example, at around $5 \mathrm{mmol} / \mathrm{L}(0.5 \mathrm{~g} / \mathrm{L}) 3-\mathrm{HP}$ initially, the extraction yield is $23 \%$ for solution $1(2.5 \mathrm{mmol} / \mathrm{L} \mathrm{OA})$, $58 \%$ for solution $2(1.0 \mathrm{mmol} / \mathrm{L} \mathrm{OA})$ and $74 \%$ for solution $3(0.0058 \mathrm{mmol} / \mathrm{L} \mathrm{OA})$. The yield decrease at low acid concentration with commercial TOA (solutions 1 and 2) is dramatic whereas with purified TOA (solution 3) the decrease is much smaller. Nevertheless, it still denotes the release of weak amounts of impurities, but with much lower importance than from unpurified TOA. In figure 7B, one 
can see a much smaller yield decrease for purified TOA (solution 3) than for solution 1 along with the increase of amine concentration, up to about $50 \% \mathrm{v} / \mathrm{v}$ TOA. This steeper decrease for unpurified TOA is due to impurities release, whereas for purified TOA only the solvating effect is noticeable.

In the case of purified TOA, results shown in Table 2 confirm that the purification of TOA was effective, dividing the amount of amines released in the aqueous phase by a factor 30 when compared to solution 2 and a factor 65 when compared to solution 1 . This decrease makes the amount of amines practically negligible in the aqueous phase, as confirmed by $\mathrm{pH}$ measurements. Besides the effects described above on the extraction chemistry, the diminution of the released amines by means of the purification step is particularly recommended if microorganisms are used in a biological process due to expected amine toxicity. For example, a similar lactate - long chains alkyl ammonium salt in an aqueous phase proved to be very toxic for several kinds of microorganisms [61]. Purification of fatty tertiary amines can be reached for example with an adsorption process as described in a US patent [62]. In continuous chemical processes, however, the presence of impurities would have less impact because the recycled organic phase would be washed by the continuous fresh aqueous flow and small amines would be readily depleted [43].

\section{Conclusion}

This paper reports a comprehensive study of the reactive extraction of 3-HP, a valuable platform molecule. The experimental approach was designed in line with a potential application of reactive extraction for the in situ product recovery of this acid. It appeared from the solvent screening experiments, performed for the first time on 3-HP, that the type of solvent has a great influence on the extraction yield, with $\mathrm{H}$-bond donor characteristic and polarity being the most important properties to increase the yield. This highlights strong interactions between the solvent and the complexes formed between acids and amines. Water solubility in the organic phase also seems to be a major factor in complex stabilization. In active diluents like $n$-decanol and oleyl alcohol, a bellshaped profile of the extraction yield as a function of amine concentration is observed with very low 

extraction process. In these solvents, the increase in initial acid concentration from 0.003 up to 0.1 $\mathrm{mol} / \mathrm{L}(0.25-10 \mathrm{~g} / \mathrm{L})$ led to an increase in extraction yield while a further increase from 0.1 to 0.56

$4 \mathrm{~mol} / \mathrm{L}(10-50 \mathrm{~g} / \mathrm{L})$ led to the reduction of the extraction yield. This phenomenon has been shown to be due to amines transfer in the aqueous phase, with significant impact for low acid concentrations. Deviation of equilibrium $\mathrm{pH}$ from what should be expected with the remaining acid in the aqueous phase demonstrated the presence of impurities. We identified the release of $n$-octylamine and di- $n$ octylamine coming from commercial TOA into the aqueous phase even with $99.6 \%$ purity. This

9 transfer reduces extraction yields at low initial acid concentrations and increases equilibrium $\mathrm{pH}$ which is, accordingly, a reliable indicator of amines concentration in water. Given the extraction yield

11 reduction and the suspected toxicity for microorganisms performing bioconversions, purification of

12 TOA before use could be necessary. These results give insights in extraction mechanisms of organic 13 acids, further clarifying the role of the organic solvent and water in the stabilization of the acid-amine 14 complex and pointing out the role of the amine impurities in extraction yield reduction and 15 biocompatibility of the extraction process. All this understanding is essential for further mechanistic and predictive modeling. 


\section{Acknowledgements}

2 The authors would like to thank AgroParisTech students of the $189^{\text {th }}$ promotion and Dr Claire Saulou-

3 Bérion for having provided valuable experimental assistance, and the Région Champagne-Ardenne,

4 the Conseil départemental de la Marne and Reims Métropole for financial support. 
[1] T. Werpy, G. Petersen, A. Aden, J. Bozell, J. Holladay, J. White, A. Manheim, D. Elliot, L. Lasure, S. Jones, M. Gerber, K. Ibsen, L. Lumberg, S. Kelley, Top Value Added Chemicals from Biomass, Volume 1-Results of Screening for Potential Candidates from Sugars and Synthesis Gas, U.S. Department of Energy, Oak Ridge, TN, 2004.

[2] J.J. Bozell, G.R. Petersen, Technology development for the production of biobased products from biorefinery carbohydrates - the US Department of Energy's "Top 10" revisited, Green Chemistry. 12 (2010) 539.

[3] T. Dishisha, L.P. Pereyra, S.-H. Pyo, R.A. Britton, R. Hatti-Kaul, Flux analysis of the Lactobacillus reuteri propanediol-utilization pathway for production of 3-hydroxypropionaldehyde, 3hydroxypropionic acid and 1,3-propanediol from glycerol, Microbial Cell Factories. 13 (2014) 111.

[4] G. Burgé, C. Saulou-Bérion, M. Moussa, B. Pollet, A. Flourat, F. Allais, V. Athès, H.E. Spinnler, Diversity of Lactobacillus reuteri Strains in Converting Glycerol into 3-Hydroxypropionic Acid, Applied Biochemistry and Biotechnology. 177 (2015) 923-939.

[5] K. Kim, S.-K. Kim, Y.-C. Park, J.-H. Seo, Enhanced production of 3-hydroxypropionic acid from glycerol by modulation of glycerol metabolism in recombinant Escherichia coli, Bioresource Technology. 156 (2014) 170-175.

[6] H.S. Chu, Y.S. Kim, C.M. Lee, J.H. Lee, W.S. Jung, J.-H. Ahn, S.H. Song, I.S. Choi, K.M. Cho, Metabolic engineering of 3-hydroxypropionic acid biosynthesis in Escherichia coli, Biotechnology and Bioengineering. 112 (2015) 356-364.

[7] V. Kumar, S. Ashok, S. Park, Recent advances in biological production of 3-hydroxypropionic acid, Biotechnology Advances. 31 (2013).

[8] E.I. Lan, D.S. Chuang, C.R. Shen, A.M. Lee, S.Y. Ro, J.C. Liao, Metabolic engineering of cyanobacteria for photosynthetic 3-hydroxypropionic acid production from $\mathrm{CO} 2$ using Synechococcus elongatus PCC 7942, Metabolic Engineering. 31 (2015) 163-170.

[9] Y. Wang, T. Sun, X. Gao, M. Shi, L. Wu, L. Chen, W. Zhang, Biosynthesis of platform chemical 3hydroxypropionic acid (3-HP) directly from CO2 in cyanobacterium Synechocystis sp. PCC 6803, Metabolic Engineering. 34 (2016) 60-70.

[10] I.-Y. Jung, J.-W. Lee, W.-K. Min, Y.-C. Park, J.-H. Seo, Simultaneous conversion of glucose and xylose to 3-hydroxypropionic acid in engineered Escherichia coli by modulation of sugar transport and glycerol synthesis, Bioresource Technology. 198 (2015) 709-716.

[11] K.R. Kildegaard, Z. Wang, Y. Chen, J. Nielsen, I. Borodina, Production of 3-hydroxypropionic acid from glucose and xylose by metabolically engineered Saccharomyces cerevisiae, Metabolic Engineering Communications. 2 (2015) 132-136.

[12] Z. Jin, S.-T. Yang, Extractive fermentation for enhanced propionic acid production from lactose by Propionibacterium acidipropionici, Biotechnology Progress. 14 (1998) 457-465.

[13] Z. Wu, S.-T. Yang, Extractive fermentation for butyric acid production from glucose by Clostridium tyrobutyricum, Biotechnology and Bioengineering. 82 (2003) 93-102.

[14] L. Zhao, J. Lin, H. Wang, J. Xie, D. Wei, Development of a two-step process for production of 3hydroxypropionic acid from glycerol using Klebsiella pneumoniae and Gluconobacter oxydans, Bioprocess and Biosystems Engineering. 38 (2015) 2487-2495.

[15] A.S. Kertes, C.J. King, Extraction Chemistry of Fermentation Product Carboxylic Acids, Biotechnology and Bioengineering. 28 (1986) 269-282.

[16] V. Bízek, J. Horáček, M. Koušová, A. Heyberger, J. Procházka, Mathematical model of extraction of citric acid with amine, Chemical Engineering Science. 47 (1992) 1433-1440.

[17] V. Bízek, J. Horáček, M. Koušová, Amine extraction of citric acid: effect of diluent, Chemical Engineering Science. 48 (1993) 1447-1457. 
[18] A. Keshav, P. Norge, K.L. Wasewar, Reactive Extraction of Citric Acid Using Tri-n-octylamine in Nontoxic Natural Diluents: Part 1-Equilibrium Studies from Aqueous Solutions, Applied Biochemistry and Biotechnology. 167 (2012) 197-213.

[19] M. Matsumoto, T. Otono, K. Kondo, Synergistic extraction of organic acids with tri-n-octylamine and tri-n-butylphosphate, Separation and Purification Technology. 24 (2001) 337-342.

[20] D. Datta, S. Kumar, Reactive Extraction of Glycolic Acid Using Tri-n-Butyl Phosphate and Tri-nOctylamine in Six Different Diluents: Experimental Data and Theoretical Predictions, Industrial \& Engineering Chemistry Research. 50 (2011) 3041-3048.

[21] H. Uslu, Ş.i. Kırbaşlar, Extraction of aqueous of malic acid by trioctylamine extractant in various diluents, Fluid Phase Equilibria. 287 (2010) 134-140.

[22] J. Prochazka, A. Heyberger, V. Bizek, M. Kousova, E. Volaufova, Amine extraction of hydroxycarboxylic acids. 2. Comparison of equilibria for lactic, malic, and citric acids, Industrial \& Engineering Chemistry Research. 33 (1994) 1565-1573.

[23] J.A. Tamada, A.S. Kertes, C.J. King, Extraction of Carboxylic Acids with Amine Extractants. 1. Equilibria and Law of Mass Action Modeling, Industrial \& Engineering Chemistry Research. 29 (1990) 1319-1326.

[24] R.-S. Juang, R.-H. Huang, Comparison of extraction equilibria of succinic and tartaric acids from aqueous solutions with tri-n-octylamine, Industrial \& Engineering Chemistry Research. 35 (1996) 1944-1950.

[25] M. Marinova, G. Kyuchoukov, J. Albet, J. Molinier, G. Malmary, Separation of tartaric and lactic acids by means of solvent extraction, Separation and Purification Technology. 37 (2004) 199207.

[26] N. Marchitan, C. Cojocaru, A. Mereuta, G. Duca, I. Cretescu, M. Gonta, Modeling and optimization of tartaric acid reactive extraction from aqueous solutions: A comparison between response surface methodology and artificial neural network, Separation and Purification Technology. 75 (2010) 273-285.

[27] A.F. Tuyun, H. Uslu, Reactive extraction of acrylic acid using trioctylamine (TOA) in versatile diluents, Desalination and Water Treatment. 55 (2015) 193-198.

[28] K. Wang, Z. Chang, Y. Ma, C. Lei, S. Jin, Y. Wu, I. Mahmood, C. Hua, H. Liu, Equilibrium study on reactive extraction of propionic acid with $\mathrm{N} 1923$ in different diluents, Fluid Phase Equilibria. 278 (2009) 103-108.

[29] S. Kumar, D. Datta, B.V. Babu, Experimental Data and Theoretical (Chemodel Using the Differential Evolution Approach and Linear Solvation Energy Relationship Model) Predictions on Reactive Extraction of Monocarboxylic Acids Using Tri-n-octylamine, Journal of Chemical \& Engineering Data. 55 (2010) 4290-4300.

[30] A. Keshav, K.L. Wasewar, S. Chand, Reactive extraction of propionic acid using tri-n-octylamine, Chemical Engineering Communications. 197 (2009) 606-626.

[31] Y.S. Aş̧̧ı, I. İnci, Extraction equilibria of propionic acid from aqueous solutions by Amberlite LA-2 in diluent solvents, Chemical Engineering Journal. 155 (2009) 784-788.

[32] A. Senol, Influence of diluent on amine extraction of pyruvic acid using Alamine system, Chemical Engineering and Processing: Process Intensification. 45 (2006) 755-763.

[33] M.E. Marti, T. Gurkan, L.K. Doraiswamy, Equilibrium and Kinetic Studies on Reactive Extraction of Pyruvic Acid with Trioctylamine in 1-Octanol, Industrial \& Engineering Chemistry Research. 50 (2011) 13518-13525.

[34] D. Pal, A. Tripathi, A. Shukla, K.R. Gupta, A. Keshav, Reactive Extraction of Pyruvic Acid Using Tri-n-octylamine Diluted in Decanol/Kerosene: Equilibrium and Effect of Temperature, Journal of Chemical \& Engineering Data. 60 (2015) 860-869.

[35] R.-S. Juang, R.-H. Huang, Equilibrium studies on reactive extraction of lactic acid with an amine extractant, Chemical Engineering Journal. 65 (1997) 47-53.

[36] G. Kyuchoukov, D. Yankov, Lactic Acid Extraction by Means of Long Chain Tertiary Amines: A Comparative Theoretical and Experimental Study, Industrial \& Engineering Chemistry Research. 51 (2012) 9117-9122. 
[37] G. Kaur, K. Elst, Development of reactive extraction systems for itaconic acid: a step towards in situ product recovery for itaconic acid fermentation, RSC Advances. 4 (2014) 45029-45039.

[38] M. Reschke, K. Schügerl, Reactive Extraction of Penicillin II: Distribution Coefficients and Degrees of Extraction, Chemical Engineering Journal. 28 (1984) B11-B20.

[39] J.A. Tamada, C.J. King, Extraction of Carboxylic Acids with Amine Extractants. 2. Chemical Interactions and Interpretations of Data, Industrial \& Engineering Chemistry Research. 29 (1990) 1327-1333.

[40] H. Uslu, Ş. İsmail Kırbaşlar, K.L. Wasewar, Reactive Extraction of Levulinic Acid by Amberlite LA2 Extractant, Journal of Chemical \& Engineering Data. 54 (2009) 712-718.

[41] A. Senol, Extraction equilibria of nicotinic acid using Alamine 336 and conventional solvents: effect of diluent, Chemical Engineering Journal. 83 (2001) 155-163.

[42] M. Moussa, G. Burgé, F. Chemarin, R. Bounader, C. Saulou-Bérion, F. Allais, H.-E. Spinnler, V. Athès, Reactive extraction of 3-hydroxypropionic acid from model aqueous solutions and real bioconversion media. Comparison with its isomer 2-hydroxypropionic (lactic) acid, Journal of Chemical Technology and Biotechnology. (2015)

[43] N.L. Ricker, C.J. King, Solvent Extraction of Wastewaters from Acetic-Acid Manufacture, Robert S. Kerr Environmental Research Laboratory (U.S. Environmental Protection Agency), Ada, OK, United States, 1980.

[44] D. Swern, H.B. Knight, T.W. Findley, Purification of oleic acid, methyl oleate, and oleyl alcohol for use as chemical intermediates, Oil \& Soap. 21 (1944) 133-139.

[45] M.A. Liebert, Final Report on the Safety Assessment of Stearyl Alcohol, oleyl Alcohol, and Octyl Dodecanol, Journal of the American College of Toxicology. 4 (1985).

[46] D.L. Lide, CRC Handbook of Chemistry and Physics, 84th ed., CRC Press, Boca Raton, FL, 2003.

[47] J. S̀liwiok, T. Kowalska, Spectroscopic and dielectric examination of the oleyl alcohol-oleic acid system, Microchemical Journal. 18 (1973) 605-612.

[48] J.P. Hawranek, A.S. Muszyński, J.Z. Flejszar-Olszewska, Infra-red dispersion of liquid trioctylamine, Journal of Molecular Structure. 436 (1997) 605-612.

[49] C.L. Yaws, P.K. Narasimhan, Thermophysical Properties of Chemicals and Hydrocarbons, Chapter 19 Dipole moments - Organic compounds, William Andrew Publishing, Norwich, NY, 2009.

[50] Y. Marcus, Wiley series in solution chemistry: volume 4, The properties of solvents, Wiley, Chichester ; New York, 1998.

[51] M. Matsumoto, K. Mochiduki, K. Kondo, Toxicity of ionic liquids and organic solvents to lactic acid-producing bacteria, Journal of Bioscience and Bioengineering. 98 (2004) 344-347.

[52] M. Vermuë, J. Sikkema, A. Verheul, R. Bakker, J. Tramper, Toxicity of homologous series of organic solvents for the gram-positive bacteria Arthrobacter and Nocardia Sp. and the gramnegative bacteria Acinetobacter and Pseudomonas Sp., Biotechnology and Bioengineering. 42 (1993) 747-758.

[53] D. Pal, A. Keshav, Recovery of Pyruvic Acid using Tri-n-butylamine Dissolved in Non-Toxic Diluent (Rice Bran Oil), Journal of The Institution of Engineers (India): Series E. (2015).

[54] T. Harington, M.M. Hossain, Extraction of lactic acid into sunflower oil and its recovery into an aqueous solution, Desalination. 218 (2008) 287-296.

[55] A. Keshav, K.L. Wasewar, S. Chand, Reactive extraction of propionic acid using tri-n-octylamine, tri-n-butyl phosphate and aliquat 336 in sunflower oil as diluent, Journal of Chemical Technology and Biotechnology. 84 (2009) 484-489.

[56] B. Choudhury, A. Basha, T. Swaminathan, Study of lactic acid extraction with higher molecular weight aliphatic amines, Journal of Chemical Technology and Biotechnology. 72 (1998) 111116.

[57] J.A. Tamada, C.J. King, Extraction of Carboxylic Acids by Amines Extractant, Lawrence Berkeley Laboratory, CA (USA), United States, 1989.

[58] J.M. Wardell, C.J. King, Solvent equilibriums for extraction of carboxylic acids from water, Journal of Chemical and Engineering Data. 23 (1978) 144-148. 
[59] L.-K. Ju, A. Verma, Characteristics of lactic acid transport in supported liquid membranes, Separation Science and Technology. 29 (1994) 2299-2315.

[60] Encyclopedia of Chemical Technology, Alkanolamines to Antibiotics, 4th edition, Kirk-Othmer, 1993.

[61] J. Cybulski, A. Wiśniewska, A. Kulig-Adamiak, L. Lewicka, A. Cieniecka-Rosłonkiewicz, K. Kita, A. Fojutowski, J. Nawrot, K. Materna, J. Pernak, Long-Alkyl-Chain Quaternary Ammonium Lactate Based Ionic Liquids, Chemistry - A European Journal. 14 (2008) 9305-9311.

[62] A. Coenen, K. Kosswig, F. Von Praun, H.-P. Schüller, Purification of tertiary amines using an adsorbent, 4255356, 1981. 